\title{
In Situ Hybridization Histochemistry of Spot 35 Protein, a Calcium-Binding Protein, in the Rat Brain
}

\author{
HIROSHI USUI, ${ }^{* 1}$ TAKASHI KATAGIRI, ${ }^{1}$ YASUJI YOSHIDA,,${ }^{1}{ }^{1}$ AKIKO \\ NISHIYAMA $\ddagger^{1}$ TOMIO ICHIKAWA, ${ }^{1}$ RYOZO KUWANO, ${ }^{2}$ YASUO \\ TAKAHASHI, ${ }^{3}$ AND TOSHIRO KUMANISHI ${ }^{1}$
}

'Department of Neuropathology, Brain Research Institute, Niigata University, Niigata 951, Japan; ${ }^{2}$ Research Laboratory for Molecular Genetics; and ${ }^{3}$ Department of Neuropharmacology, Brain Research Institute, Niigata University, Niigata 951, Japan; †: Present Address: †Department of Neuropathology, Hirosaki University, Hirosaki 036, Japan and $\neq$ La Jolla Cancer Research Foundation, 10901 North

Torrey Pines Road, La Jolla, CA 92037, USA

Received February 26, 1991; Accepted June 8, 1991

\begin{abstract}
Using in situ hybridization, we analyzed the localization of mRNA for Spot 35 protein (Spot 35), a calcium-binding protein of the EF-hand type, in the rat cerebellum at various developmental stages. A cDNA fragment corresponding to part of the 3 '-noncoding region was ${ }^{35}$ S-labeled and used as a hybridization probe. Autoradiographic signals for Spot 35 mRNA were detected in all the Purkinje cells, but not in any other neurons or glial cells in the adult rat cerebellum. There was no significant difference in signal intensity among individual cells. The signals were observed exclusively in Purkinje cell bodies, but not in their processes, in striking contrast to previous immunohistochemical studies in which Spot 35 protein was demonstrated in both cell bodies and processes. In the time-course study, signals for Spot 35 mRNA were detected in Purkinje cell bodies weakly at embryonic day 19, thereafter more intensely at more developed stages and
\end{abstract}

${ }^{*}$ Author to whom all correspondence and reprint requests should be addressed. 
most intensely at postnatal days 30 and 60 (adulthood). The signal intensities of individual cells were similar at each of these developmental stages except for the very early stages at which signals were weak and slightly variable among cells. These findings, especially that of the characteristic coordinated expression of Spot 35 mRNA at given stages, should prove useful in studies of degenerative diseases in the cerebellum in experimental animals and man. A weak expression of Spot 35 mRNA in some of non-Purkinje cells was also noted.

Index Entries: In situ hybridization; spot 35 protein; calciumbinding protein; Purkinje cell; gene expression; mRNA; calbindin; cerebellum.

\section{INTRODUCTION}

Spot 35 protein (Spot 35) was originally discovered in the rat cerebellum by Yoshida and Takahashi in the course of a systematic analysis of brain-soluble proteins by two-dimensional polyacrylamide gelelectrophoresis (2D-PAGE) (Yoshida and Takahashi, 1980). They detected Spot 35 only in the cerebellum and not in other brain regions or nonneuronal tissues. Subsequent immunohistochemical studies have revealed that Spot 35 is localized in the Purkinje cells of the cerebellum in rat (Yamakuni et al., 1984) as well as in other mammals including man (Usui et al., unpublished data). Spot 35 is considered to be a calciumbinding protein, as suggested by its calcium-binding capacity (Yamakuni et al., 1985) and the presence of calcium-binding EF-hand regions in its amino acid sequence (Yamakuni et al., 1987). Electrophysiological findings suggesting that Spot 35 may be involved in modulation of neuronal activities of Purkinje cells have also been obtained (Maruyama et al., 1985). It is therefore likely that Spot 35 plays an important and unique role in the physiological function of Purkinje cells.

In the present study, we used the cDNA fragment of Spot 35 as a probe and carried out in situ hybridization histochemistry to investigate Spot 35 gene expression in individual cells at various developmental stages.

\section{MATERIALS AND METHODS}

\section{Preparation of cDNA Probe}

Molecular cloning and nucleotide sequence of cDNA to Spot 35 mRNA have been previously described (Yamakuni et al., 1986, 1987). In the present study, the cDNA fragment corresponding to the 3 '-noncoding region was prepared and used as a hybridization probe. Briefly, the Rsal-Rsal cDNA fragment (Fig. 1), which corresponds to base No. 960-1556 of the cDNA sequence described (Yamakuni et al., 1986, 1987), was subcloned into the Smal cloning site of plasmid vector pSPT18 and 


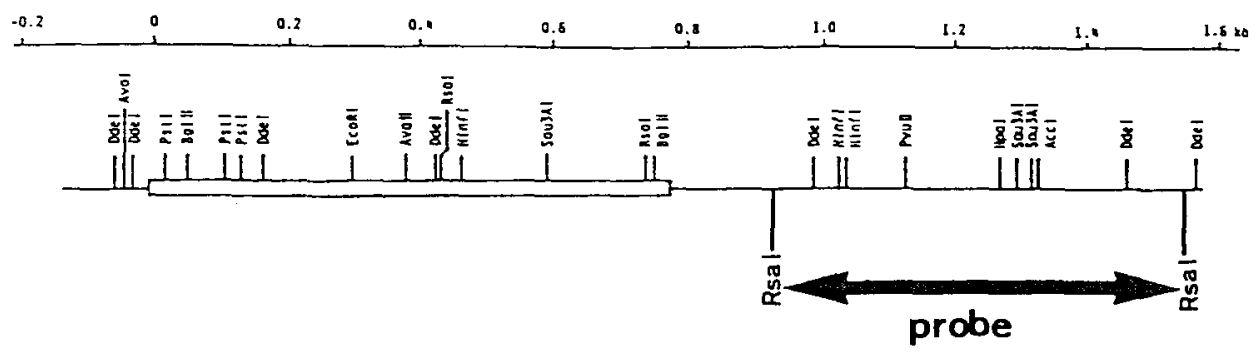

Fig. 1. Restriction endonuclease map of cDNA for rat Spot 35. The protein-coding region is indicated by the open box. The Rsal-Rsal cDNA fragment of the $3^{\prime}$-noncoding region, indicated by an arrow, was used as a probe for in situ hybridization histochemistry. The cDNA fragment corresponds to base No. 960-1556 of the cDNA sequence described (Yamakuni et al., 1986, 1987).

propagated in DH1 host cells. The cDNA-vector recombinant was isolated by alkaline extraction, purified by cesium chloride equilibrium centrifugation (Sambrook et al., 1989), and doubly digested with restriction enzymes at the Kpnl and BamHl sites, adjacent to the cDNA insert. The cDNA fragment was purified by polyacrylamide gel electrophoresis and electroelution, labeled with $\left.{ }^{35} \mathrm{~S}\right] \mathrm{dATP}\left(5 \times 10^{8} \mathrm{cpm} / \mu \mathrm{g} \mathrm{cDNA}\right)$ by the random primer method, and used as a probe for in situ hybridization. Linearized plasmid vector DNA without an insert was similarly labeled and used as a control probe.

\section{Animals}

Inbred Wistar rats were obtained from a commercial dealer. Female rats mated with males were checked daily and the day of sperm positivity was counted as Embryonic Day 0 (E0). The day of birth was counted as Postnatal Day $0(\mathrm{P} 0)$. In the developmental study, the rats were examined at E15, E17, E19, P0, P5, P10, P15, P30, and P60.

\section{In Situ Hybridization Procedure}

The brain tissues were removed from the anesthetized rats and immediately embedded and frozen in O.C.T. compound (Miles Laboratories Inc., Kankakee, IL, USA) at $-15^{\circ} \mathrm{C}$. Sagittal and coronal sections, $16-\mu \mathrm{m}$ thick, were made on a cryostat, attached to $0.01 \%$ poly-Llysine-coated slide glass, and fixed in $4 \%$ paraformaldehyde/phosphate buffered saline (PBS) for $30 \mathrm{~min}$. The sections were washed with PBS containing $2 \mathrm{mg} / \mathrm{mL}$ glycine for $20 \mathrm{~min}$, and acetylated in $0.25 \%$ acetic anhydride $/ 0.1 \mathrm{M}$ Tris $\mathrm{HCl}(\mathrm{pH} \mathrm{8.0)}$ for $10 \mathrm{~min}$, followed by washing with $2 \times$ SSC $(1 \times$ SSC; $0.15 M \mathrm{NaCl}, 0.015 \mathrm{M}$ sodium citrate) for $5 \mathrm{~min}$ three times. The sections were then prehybridized for $2-4 \mathrm{~h}$ at room temperature in prehybridization solution containing $50 \%$ formamide, $5 \times$ SSC, 50 $\mathrm{m} M$ sodium phosphate $(\mathrm{pH} 6.5), 2 \%$ Sarkosyl, $1 \times$ Denhardt's solution $(0.02 \%$ Ficoll, $0.02 \%$ polyvinylpyrrolidone, $0.02 \%$ bovine serum albu- 
$\mathrm{min}), 250 \mu \mathrm{g} / \mathrm{mL}$ heat-denatured salmon sperm DNA, and $10 \mathrm{mM}$ $\beta$-mercaptoethanol; and hybridized for $12-24 \mathrm{~h}$ at $37^{\circ} \mathrm{C}$ in a solution containing $4 \mathrm{vol}$ of prehybridization solution, 1 vol of $50 \%$ dextran sulfate, and $0.1 \mu \mathrm{g} / \mathrm{mL}$ heat-denatured radiolabeled DNA probe. After hybridization, the tissue sections were washed briefly with $2 \times$ SSC at room temperature, followed by $0.1 \times \mathrm{SSC} / 0.1 \%$ Sarkosyl at $37^{\circ} \mathrm{C}$ for 40 min three times. They were then dehydrated, processed for autoradiography using NTB-2 nuclear track emulsion (Kodak, Rochester, NY, USA), and exposed for $10-30 \mathrm{~d}$ at $4^{\circ} \mathrm{C}$. Some sections were lightly counterstained with hematoxylin.

\section{RESULTS}

The DNA fragment of the 3'-noncoding region of rat Spot 35 cDNA (Fig. 1), which corresponds to base No. 960-1556 of the cDNA sequence reported by Yamakuni et al. (Yamakuni et al., 1986, 1987), was used as a probe to enhance the probe specificity. We preliminarily examined the reactivity of this cDNA probe by Northern blot hybridization with the same stringency as that used for the present in situ hybridization analysis and detected a single major hybridized band in rat cerebellar RNA, which was about $1.9 \mathrm{~kb}$ in length (data not shown), corresponding to the size of Spot 35 mRNA (Yamakuni et al., 1986, 1987).

When the adult rat cerebellum (P30 and P60) was examined by in situ hybridization with the ${ }^{35} \mathrm{~S}$-labeled probe, the accumulation of autoradiographic silver grains representing the signals for the expression of Spot 35 mRNA was detected in all the Purkinje cells, but not in any other neurons or glial cells in the cerebellum. In the Purkinje cells, the silver grains for Spot 35 mRNA were observed exclusively in cell bodies, and the signal intensity was not significantly different among individual cells and between those in the hemisphere and vermis. However, the axons and dendrites of Purkinje cells revealed no significant accumulation of silver grains. Figure 2A shows the specific localization of intense silver grains in Purkinje cell somata after $10 \mathrm{~d}$ of autoradiographic exposure. Essentially identical findings were obtained in sections treated with the higher stringency conditions of washing $\left(0.1 \times \mathrm{SSC}, 55^{\circ} \mathrm{C}\right)$ or prolonged exposure (data not shown). When the control probe (radiolabeled linearized vector DNA fragment) was used for hybridization, no significant accumulation of silver grains was detected in any brain region, as shown in Fig. 2B.

In the time-course study, the rat cerebella at developmental stages gradually accumulated more silver grains in the Purkinje cells. In Figs. 3 and 4 , the accumulations of the silver grains at the representative stages are shown. Silver grains observed very weakly at P0 gained in intensity up to P30, when sections were exposed for $2 \mathrm{wk}$ (Fig. 3). When the sections were exposed for $1 \mathrm{mo}$, clusters of silver grains were detected in 


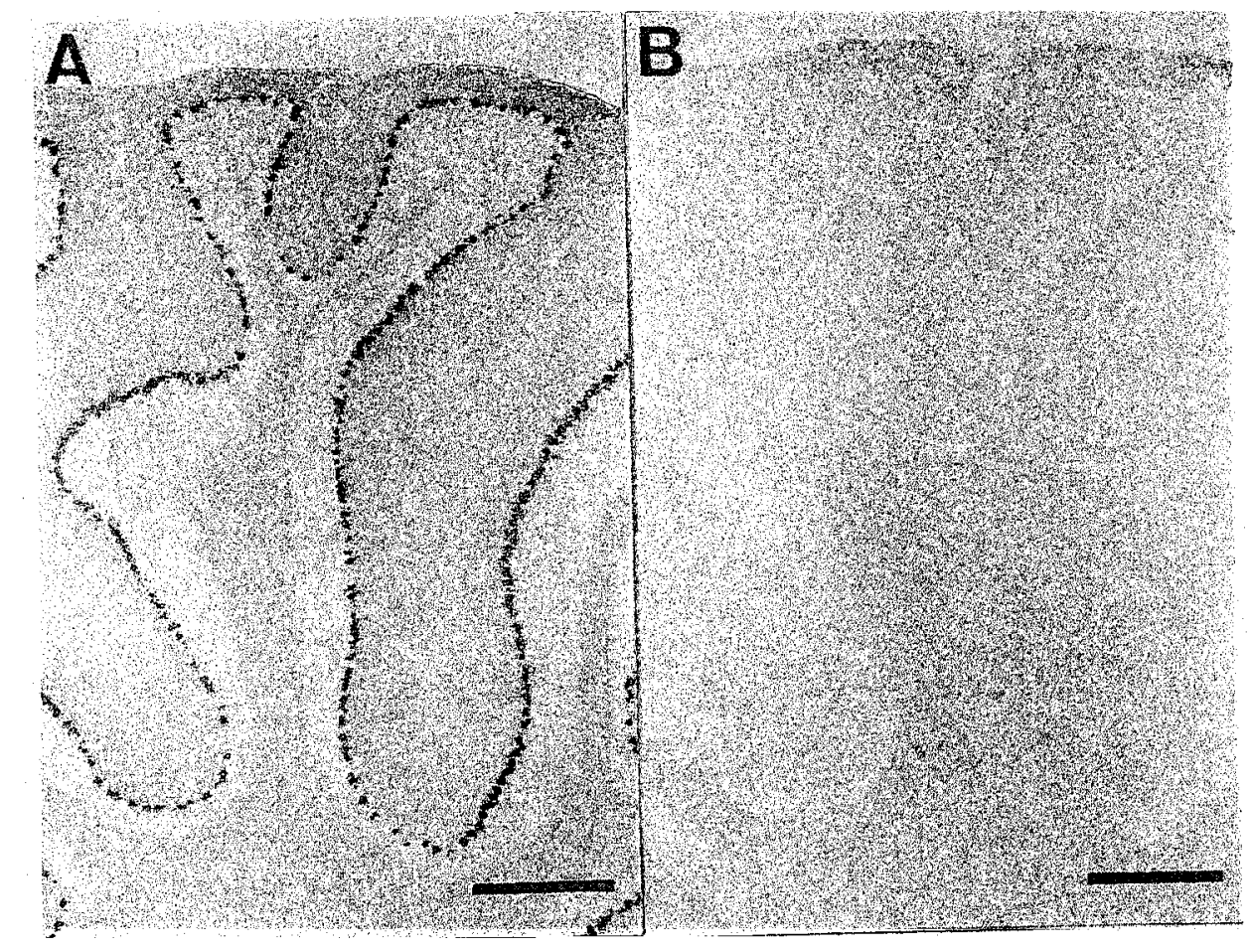

Fig. 2. In situ hybridization of the adult rat cerebellum with ${ }^{35} \mathrm{~S}$-labeled Spot 35 cDNA probe. A: Specific localization of silver grains for Spot $35 \mathrm{mRNA}$ in Purkinje cell bodies. B: Control section processed with plasmid DNA probe. Ten days autoradiographic exposure. Magnification bars: $500 \mu \mathrm{m}$.

Purkinje cells even at E19, and more clearly at birth (P0) (Fig. 4). However, no significant deposition of silver grains was found at E17 and E15. As in adult cerebellum, signals were observed in all the Purkinje cells at each of the given developmental stages and, except for the very early stages at which the signals were weak and slightly variable among cells, the accumulation densities of the silver grains were similar among individual Purkinje cells. This finding represents a coordinated increase of Spot 35 mRNA in Purkinje cells through development.

In the adult rat brain, the silver grains were indistinct in other regions of the brain after $10 \mathrm{~d}$ of autoradiographic exposure. However, when the sections were exposed for 1 mo, weak but unequivocal accumulations of silver grains were observed in some non-Purkinje neurons including those in the hippocampus, caudate-putamen, amygdaloid nucleus, ventral nucleus of thalamus, medial mammillary nucleus, medial geniculate nucleus, substantia nigra, pretectal area, and pontine nucleus (Fig. 5). Similar signals were also observed in sections reacted under higher stringent condition (data not shown), but never observed in any of control sections. It was most likely that Spot 35 mRNA was actually, though weakly, expressed in some non-Purkinje cells. 


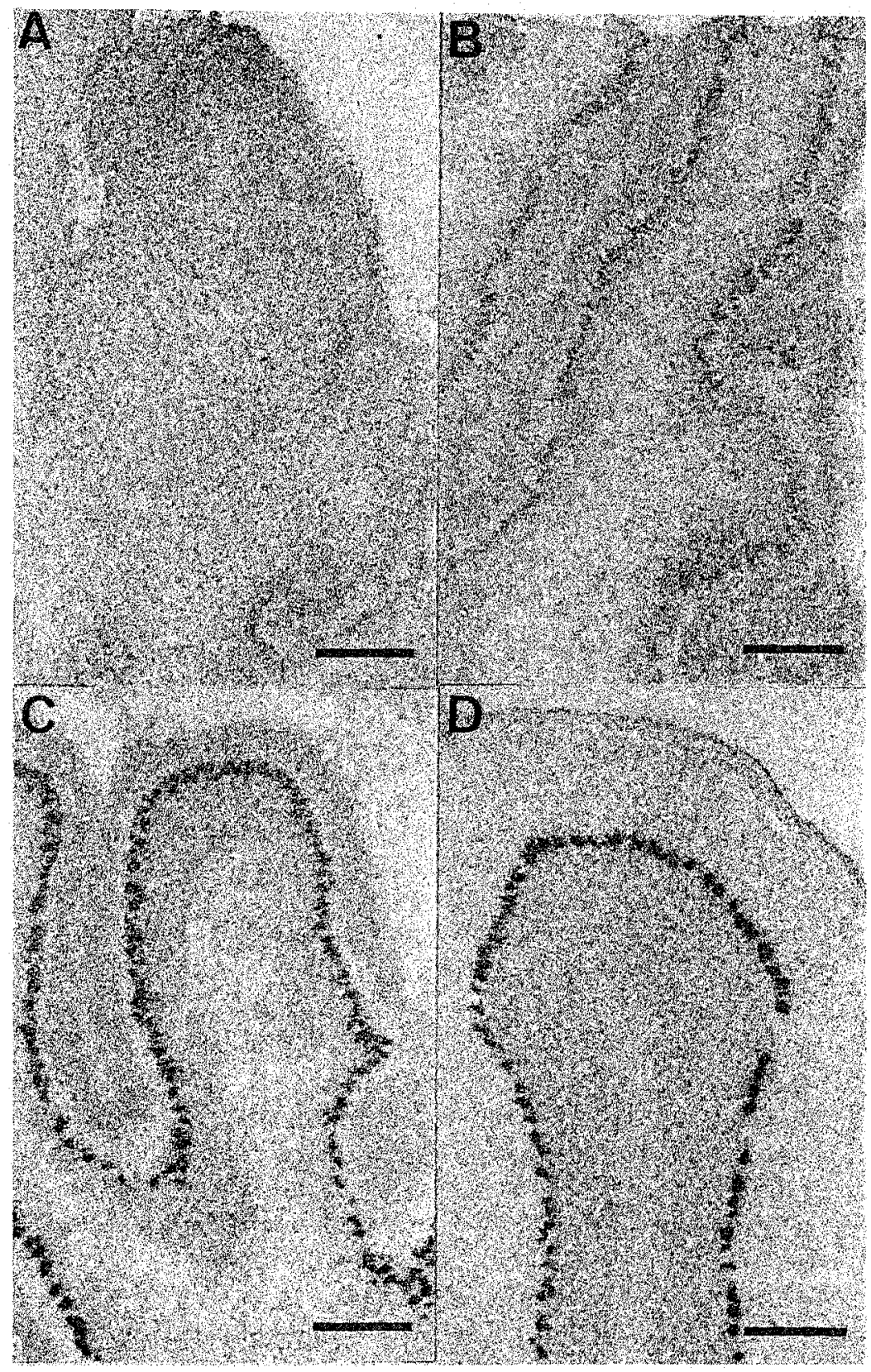

Fig. 3. Spot 35 mRNA expression at different developmental stages in the rat cerebellum. Note the gradual increase of silver grains in Purkinje cells during developmental stages. A, P0; B, P5; C, P10; and D, P30. Two weeks autoradiographic exposure. Lightly counterstained with hematoxylin. Magnification bars: $200 \mu \mathrm{m}$. 


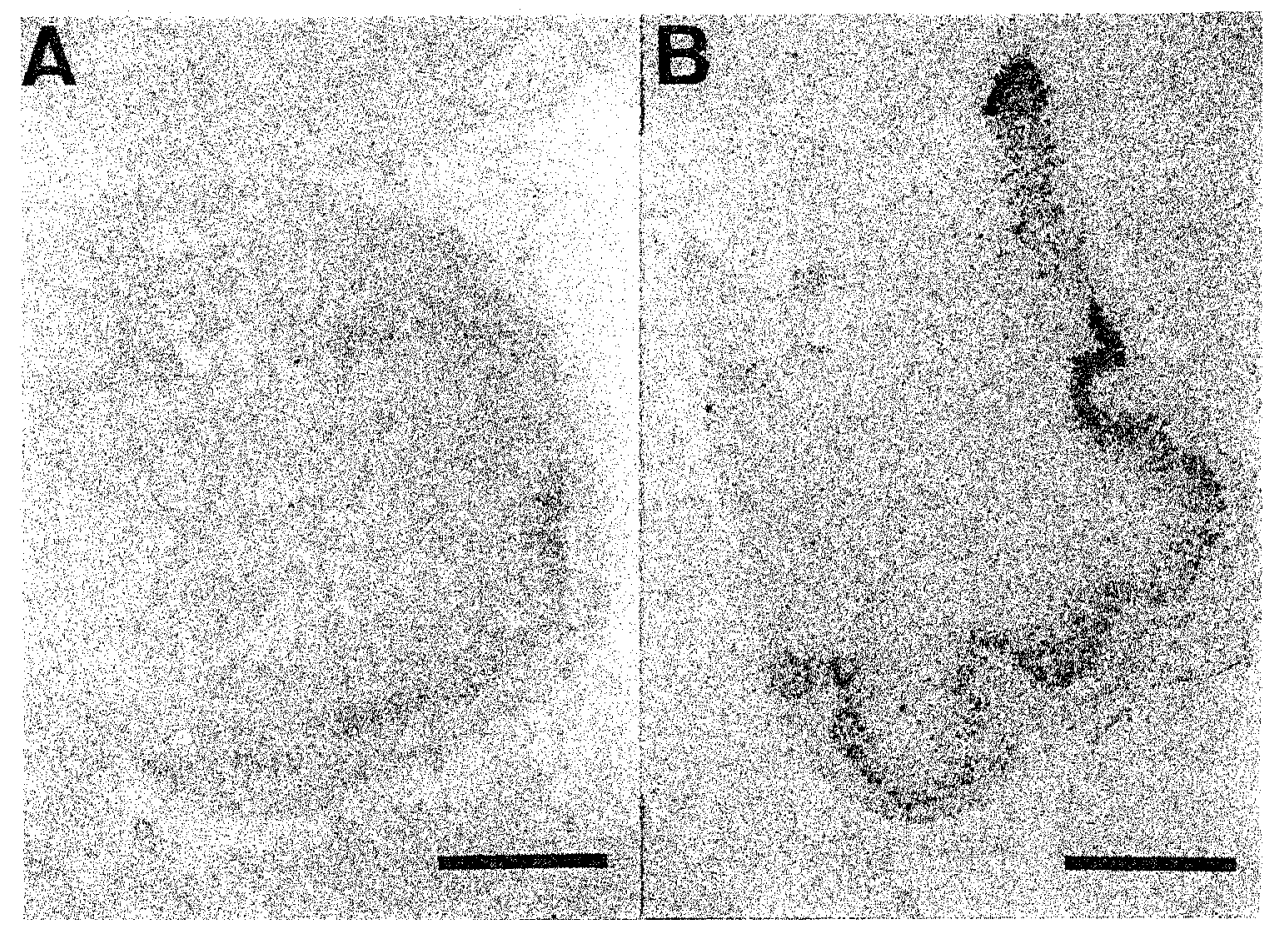

Fig. 4. Detection of Spot $35 \mathrm{mRNA}$ at early developmental stages by prolonged autoradiographic exposure. The hybridized sections were exposed for 4 wk. Silver grains in Purkinje cells are seen from F19. A, F19 and B, P0. Magnification bars: $400 \mu \mathrm{m}$.

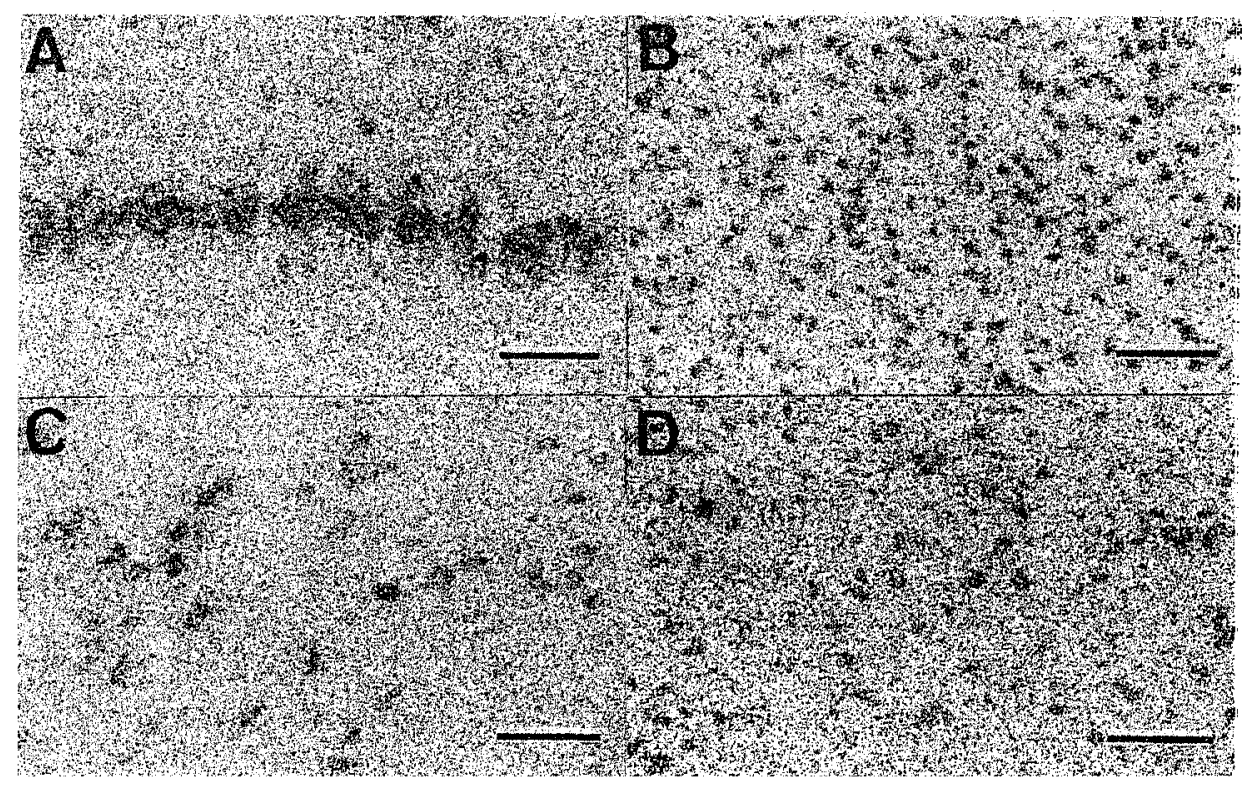

Fig. 5. Detection of weak expression of Spot 35 mRNA in non-Purkinje neurons by prolonged autoradiographic exposure. Silver grains are seen in some of non-Purkinje neurons in the cerebrum and brain stem of adult rat. The hybridized sections were exposed for 4 wk. A, hippocampal CA1 field; B, caudate-putamen; $\mathbf{C}$, substantia nigra and D, geniculate nucleus. Magnification bars: $100 \mu \mathrm{m}$. 


\section{DISCUSSION}

The previous sequence analysis of rat Spot 35 cDNA has revealed that Spot 35 belongs to the calcium-binding protein family of the EF-hand type, which includes calmodulin, S-100 protein, parvalbumin, troponin C, calretinin, and others (Yamakuni et al., 1986, 1987). When the nucleotide sequence of Spot 35 is compared with that of calbindin D28, which has recently been isolated from a newborn rat brain library (Hunziker and Schrickel, 1988), a high homology can be seen in the coding region. Although there are some differences in the $5^{\prime}$ - and $3^{\prime}$-noncoding regions, it seems possible that Spot 35 is identical to calbindin D28. The previous observation that Spot 35 gene is single (Yamakuni et al., 1988) also makes this possibility likely.

In the present study, we analyzed the pattern of Spot 35 mRNA expression at the cellular level during the developmental stages of the cerebellum. We used a cDNA fragment of the $3^{\prime}$-noncoding region of Spot 35 as a probe for in situ hybridization to exclude possible crosshybridization with mRNAs of other EF-hand calcium-binding proteins.

On examination of the adult rat cerebellum, Spot 35 mRNA was detected specifically and intensely in the cell bodies of all the Purkinje cells in each section. There was no significant difference in signal intensity either among individual Purkinje cells or between those in the hemisphere and the vermis, suggesting that Spot 35 is expressed to a similar extent in all the Purkinje cells. This also suggests that Spot 35 is necessary to a similar extent in all the Purkinje cells for ordinary function. In these Purkinje cells, Spot 35 mRNA is selectively localized in the cell bodies and not in the processes. This is in striking contrast to the previous immunohistochemical study in which Spot 35 immunoreactivity was shown in both cell bodies and the full extent of the dendrites and axons of Purkinje cells (Yamakuni et al., 1984). This apparent discrepancy in intracellular localization of Spot $35 \mathrm{mRNA}$ and protein indicated that this protein is transported from the site of biosynthesis (soma) and utilized in remote sites (cell processes).

In the time-course study, signals for Spot 35 mRNA were detected in Purkinje cell bodies weakly at E19, thereafter more intensely at more developed stages and most intensely at P30 and P60. At each of these developmental stages including E19, the signals were observed in all the Purkinje cells and, except for the very early stages, the signal intensities of individual cells were similar in the same as well as among the different cerebellar regions. Thus, as in adult rat cerebellum, Purkinje cells during developmental stages also showed coordinated expression of Spot 35 mRNA.

The previous quantitative studies have shown that the amount of Spot 35 mRNA in the cerebellar tissues gradually increased during development (Yamakuni et al., 1985, 1988). Using dot blot hybridization, Spot 35 mRNA was first detectable around P5 and gradually increased until 
P30 (Yamakuni et al., 1988). In vitro translation using the reticulocyte lysate system has also suggested the postnatal appearance and increase of Spot 35 mRNA (Yamakuni et al., 1985). The present study clearly localized Spot 35 mRNA in Purkinje cells and detected it from E19, much earlier than P5 in the previous quantitative work. It is also shown that the previous observations should have resulted from a coordinated increase of Spot 35 mRNA in individual Purkinje cells, but not from an average increase of mRNA from Purkinje cells with different levels of mRNA expression.

Although the dot blot assay in the previous study has shown that Spot 35 mRNA is detected exclusively in the cerebellar tissue and is hardly detectable in other brain regions (Yamakuni et al., 1988), we observed weak, but distinct, signals for Spot 35 mRNA in some neurons in the cerebrum and the brain stem. Since we used a highly specific 3 'noncoding probe and obtained similar findings in sections reacted under highly stringent condition (data not shown), the weak signals observed in this study seem to indicate actual expression of Spot 35 mRNA at a lower level, but not cross-hybridization of other homologous mRNAs. Thus, it seems likely that some non-Purkinje cells can also express Spot 35 mRNA. Further extensive studies including a complete survey of in situ mapping will be worthwhile for better understanding of these neurons and also details of the biological nature of Spot 35 .

There are a number of degenerative diseases of the cerebellum both in man and animals, in most of which Purkinje cells are directly or indirectly involved. Although extensive studies have already been carried out on all of these diseases, their pathogenesis remains largely unknown. To approach this problem, analysis of Spot 35 might be of value, inasmuch as this protein may play an important role in the ordinary functions of Purkinje cells and also in network formation with adjacent neural elements. Our present observations, especially that of coordinated expression of Spot 35 mRNA in Purkinje cells at a given developmental and adult stage, may provide a basis for further studies including monitoring unusual changes occurring in the Purkinje cell population in cerebellar degenerative conditions.

\section{ACKNOWLEDGMENT}

We are grateful to Mrs. A. Mitsui and Mrs. C. Honma of our laboratory for their skillful technical assistance.

\section{REFERENCES}

Hunziker W., and Schrickel S. (1988) Rat brain calbindin D28: Six domain structure and extensive amino acid homology with chicken calbindin D28. Mol. Endocrinol. 2, 465-473. 
Maruyama S., Zhang G., Tamura Y., Yamakuni T., and Takahashi Y. (1985) Involvement of spot 35 protein, a cerebellar protein, in modulation of Purkinje cell activity of the rat cerebellum. Eur. J. Pharmacol. 108, 309-313.

Sambrook J., Fritsh E. F., and Maniatis T. (1989) Molecular cloning: A laboratory manual (2nd ed.) pp. 1.33-1.45. Cold Spring Harbor Laboratory, Cold Spring Harbor, NY.

Yamakuni T., Araki K., and Takahashi Y. (1985) The developmental;changes of mRNA level for a cerebellar protein (spot 35 protein) in rat brain. FEBS Lett. $188,127-130$.

Yamakuni T., Kuwano R., Araki K., Usui H., Inoue Y., and Takahashi Y. (1988) Developmental and regional changes of mRNA for a cerebellar protein (Spot 35 ) in the rat brain. J. Neurochem. 50, 282-284.

Yamakuni T., Kuwano R., Odani S., Miki N., Yamaguchi K., and Takahashi Y. (1986) Nucleotide sequence of cDNA to mRNA for a cerebellar Ca-binding protein, spot 35 protein. Nucleic Acids Res. 14, 6768.

Yamakuni T., Kuwano R., Odani S., Miki N., Yamaguchi K., and Takahashi Y. (1987) Molecular cloning of cDNA to mRNA for a cerebellar spot 35 protein. J. Neurochem. 48, 1590-1596.

Yamakuni T., Usui H., Iwanaga T., Kondo H., Odani S., and Takahashi Y. (1984) Isolation and immunohistochemical localization of a cerebellar protein. Neurosci. Lett. 45, 235-240.

Yoshida Y., and Takahashi Y. (1980) Compositional changes in soluble proteins of cerebral mantle, cerebellum, and brain stem of rat brain during development: A two-dimensional gel electrophoretic analysis. Neurochem. Res. 5, 81-95. 